\title{
CHARACTERIZATION OF MYASTHENIA GRAVIS USING CLINICAL CLASSIFICATION AND REPETITIVE NERVE STIMULATION
}

\author{
Tho Kieu Anh PHAM ${ }^{1}$, Van De TRAN ${ }^{1} \bowtie$, Kien Trung NGUYEN ${ }^{1}$, Phuong Van PHAM ${ }^{2}$, \\ Tam Thai Thanh TRAN ${ }^{1}$, Rebecca S. DEWEY ${ }^{3}$, Binh Thanh NGUYEN ${ }^{4}$, Tung Dinh LE ${ }^{4}$ \\ ${ }^{1}$ Can Tho University of Medicine and Pharmacy, Can Tho, Vietnam \\ ${ }^{2}$ Can Tho General Hospital, Can Tho, Vietnam \\ ${ }^{3}$ University of Nottingham, Nottingham, United Kingdom \\ ${ }^{4}$ Hanoi Medical University, Hanoi, Vietnam
}

Received 26 March 2021, Accepted 13 May 2021 hitps://doi.org/10.31688/ABMU.2021.56.2.04

\begin{abstract}
Introduction. Nerve stimulation tests are crucial in the early diagnosis and monitoring of neuromuscular disease.

The objective of the study was to clinically characterize and validate repetitive nerve stimulation (RNS) testing in patients with the chronic autoimmune neuromuscular disease, myasthenia gravis (MG).

Material and methods. Clinical assessment and RNS testing were performed in 30 myasthenic patients. Clinical assessments were classified using the Myasthenia Gravis Foundation of America (MGFA) clinical classification.
\end{abstract}

Results. 30 myasthenic patients were recruited, with a mean age of $48.57 \pm 2.4$ years and a female/male ratio of 2/1. MGFA classification placed 7 patients in group I (23.3\%), 7 in group IIa (23.3\%), 7 in group IIb (23.3\%), 6 in group IIIa (20\%), 2 in group IIIb (6.7\%), and 1 in group IVa (3.3\%). Additionally, $73.3 \%$ of patients had positive acetylcholine receptor (AChR) antibodies, and 20\% had been diagnosed with thymoma. The RNS
Résumé

Caractérisation de la myasthénie grave à l'aide de la classification clinique et de la stimulation répétitive nerveuse

Introduction. Les tests de stimulation nerveuse sont essentiels pour le diagnostic précoce et le suivi des maladies neuromusculaires.

L'objectif de l'étude était de caractériser et de valider cliniquement les tests de stimulation nerveuse répétitive (RNS) chez des patients atteints de la maladie neuromusculaire auto-immune chronique, la myasthénie grave (MG).

Matériel et méthodes. Une évaluation clinique et des tests RNS ont été réalisés chez 30 patients myasthéniques. Les évaluations cliniques ont été classées selon la classification clinique de la Myasthenia Gravis Foundation of America (MGFA).

Résultats. 30 patients myasthéniques ont été sélectionnés, avec un âge moyen de $48.57 \pm 2.4$ ans et un rapport femme/homme de 2/1. La classification MGFA 
test was positive in 21 patients (70\%). Patients with involvement limited to the orbicularis oculi muscles (group I) had a positive RNS test rate of $42.9 \%$, whereas this rate increased to $64.2 \%$ in patients where the limbs and truncal muscles were affected ("a" groups: IIa, IIIa, IVa). Where respiratory and pharyngeal muscles were affected ("b" groups: IIb, IIIb), patients had a $100 \%$ positive RNS test rate. A statistically significant association was found between RNS test results and AChR antibody levels $(\mathrm{p}=0.0041)$.

Conclusions. These findings are of interest for physicians treating MG patients and administering RNS testing and suggest an alternative method for the diagnosis and monitoring of $\mathrm{MG}$, in cases where $\mathrm{AChR}$ antibody quantitation is not appropriate.

Keywords: myasthenia gravis, repetitive nerve stimulation, neuromuscular autoimmune disease, AChR antibody.

\author{
List of abbreviations: \\ RNS - repetitive nerve stimulation \\ $\mathrm{MG}$ - myasthenia gravis \\ MGFA - Myasthenia Gravis Foundation of America \\ AchRs - acetylcholine receptors \\ MuSK - muscle-specific tyrosine kinase \\ LRP4 - lipoprotein receptor-related protein \\ SF EMG - single fibre electromyography \\ CMAPs - compound muscle action potentials
}

\section{INTRODUCTION}

Myasthenia gravis (MG), a chronic autoimmune neuromuscular disease, is characterized by diurnal fluctuating skeletal muscle fatigability, leading to skeletal muscle weakness. The Myasthenia Gravis Foundation of America (MGFA) categorizes MG into groups based on the clinical characteristics of the disease, namely involvement limited only to orbicularis oculi muscle weakness, weakness of the limbs and truncal muscles, and respiratory and pharyngeal muscle weakness ${ }^{1}$. Serologically, MG patients commonly possess autoantibodies including acetylcholine receptors (AChR), muscle-specific tyrosine kinase (MuSK), and low-density lipoprotein receptor-related protein (LRP4) ${ }^{2}$. Among these, AChR antibodies are present in $80-85 \%$ of MG patients ${ }^{3}$. Clinically, MG symptoms vary based on gender and age at onset. In patients under the age of 50 years, females more commonly present with MG than males, whereas, conversly, in the over-50s, males are more frequently diagnosed than females ${ }^{4}$. MG patients aged over 50 years commonly present a placé 7 patients dans le groupe I (23,3\%), 7 dans le groupe IIa (23,3\%), 7 dans le groupe IIb (23,3\%), 6 dans le groupe IIIa (20\%), 2 dans le groupe IIIb (6,7\%) et 1 dans le groupe IVa (3,3\%). De plus, 73,3\% des patients avaient des anticorps anti-récepteurs d'acétylcholine (AChR) positifs et 20\% avaient reçu un diagnostic de thymome. Le test RNS était positif chez 21 patients (70\%). Les patients ayant une atteinte limitée aux muscles orbiculaires oculi (groupe I) avaient un taux de test RNS positif de $42,9 \%$, alors que ce taux augmentait à $64,2 \%$ chez les patients où les membres et les muscles du tronc étaient touchés (groupes "a": IIa, IIIa, IVa). Là où les muscles respiratoires et pharyngés étaient affectés (groupes "b": IIb, IIIb), les patients avaient un taux de test RNS positif de $100 \%$. Une association statistiquement significative a été trouvée entre les résultats des tests RNS et les niveaux d'anticorps AChR ( $p=$ 0,0041).

Conclusions. Ces résultats sont intéressants pour les médecins traitant des patients atteints de MG et administrant des tests RNS et suggèrent une méthode alternative pour le diagnostic et la surveillance de la $\mathrm{MG}$, dans les cas où la quantification des anticorps AChR n'est pas appropriée.

Mots-clés: myasthénie grave, stimulation nerveuse répétitive, maladie auto-immune neuromusculaire, anticorps AChR.

with orbicularis oculi muscle and body muscle weaknesses, and typically exhibit more severe symptoms than younger patients . $^{5}$

Together with serum autoantibody concentration tests, nerve stimulation tests are important in the early diagnosis and monitoring of neuromuscular diseases. To this end, the repetitive nerve stimulation (RNS) test and single fibre electromyography (SF EMG) have long been used in MG diagnosis ${ }^{6,7}$. SF EMG has a sensitivity of as high as $98 \%^{8}$ or $100 \%{ }^{9}$ in the diagnosis of MG. Clinically, the non-invasive RNS test is generally recommended in MG treatment guidelines $^{10}$. However, RNS has been shown to have sensitivities of only $32-46 \%$ in orbicularis oculi muscle $^{11}$ and $84 \%$ for body muscle ${ }^{12}$.

THE OBJeCtIVE OF THE STUdY was to clinically characterize and validate RNS test results, together with their associations, in MG patients. A descriptive analyis was conducted in $30 \mathrm{MG}$ patients in Can Tho city, Vietnam. Their characteristics were recorded, and relationships between RNS test results and associated variables were examined. 


\section{Materials AND MEthods}

\section{Subjects}

The sample comprised $30 \mathrm{MG}$ patients presenting at Can Tho General Hospital from April 2019 to August 2020. The sample size was calculated based on a $95 \%$ confidence level and $\mathrm{p}=0.98$ (the sensitivity of the SF EMG measure ${ }^{8}$ ).

Inclusion criteria followed the standard guidelines for MG diagnosis ${ }^{5,13}$ : (1) history of MG diagnosis, (2) clinical symptoms of muscle weakness (e.g., ptosis, dysphagia, dysarthria) that improved with anticholinesterase agents, (3) a positive AChR test, and (4) a positive RNS test. The exclusion criteria were the presence of neuronal damage and any other condition involving muscle weakness.

\section{Analysis}

For each patient in the sample, their (1) gender (male, female), (2) age at MG onset $(<50$ and $\geq 50$ years old) $)^{2,14}$, (3) clinical symptoms, (4) MG category (based on MGFA classification, see Table 1 for details), (5) AChRs test results (a positive test being signified by a concentration of $\geq 0.52 \mathrm{nmol} / \mathrm{L}$ ), and (6) RNS test results were recorded.

RNS testing was conducted following the procedure outlined by the American Association of Neuromuscular \& Electrodiagnostic Medicine. Briefly, 10 bilateral repetitive stimulations were performed using an electrodiagnostic system (Nicolet VikingQuest EMG/NCS/EPSystem, Natus Neurology, USA). Stimulation was administered with a frenquency of $3 \mathrm{~Hz}$, in 3 main nerve-muscle groups: the facial nerve and frontalis muscle, the accessory nerve and trapezius, and the ulnar nerve and abductor digiti minimi ${ }^{16}$. All patients ceased using anticholinesterase agents for $12 \mathrm{~h}$ prior to testing. To obtain compound muscle action potentials (CMAPs) from the frontalis, the active recording electrode was placed $2 \mathrm{~cm}$ above the eyebrow, and the reference electrode was placed between the eyebrows. For the trapezius and abductor digiti minimi measurement, the surface recording electrodes were positioned in a belly-tendon montage. The facial, accessory, and ulnar nerves were stimulated at the temporomandibular joint, behind the sternocleidomastoid muscle, and at the wrist, respectively. A positive (abnormal) was characterized by a decrease in CMAP amplitude of more than $10 \%$ between the first and fourth or fifth stimuli in at least 2 muscles $^{17}$.

The study was approved by the ethical committee of Hanoi Medical University (IRB00003121, reference NCS04/DHYHN-HDDD) on the $29^{\text {th }}$ of March 2019. All participants gave informed consent prior to participation in the study.

\section{Statistical analysis}

Statistical analysis was conducted using SPSS 22.0 software (IBM, USA). An ANOVA was used to compare predictor variables across groups, and a Chi-square test (or Fisher's exact test) was used to calculate comparisons between groups. A p-value of less than 0.05 was considered statistically significant.

Table 1. Myasthenia Gravis Foundation of America (MGFA) Clinical Classification ${ }^{15}$

\begin{tabular}{cl}
\hline Class & Clinical symptoms \\
\hline I & Any ocular weakness \\
\hline II & Mild Weakness. May also have ocular muscle weakness of any severity \\
\hline IIa & $\begin{array}{l}\text { Predominantly affecting limb, axial muscles, or both. May also have lesser involvement of oropharyngeal, } \\
\text { respiratory muscles or both }\end{array}$ \\
\hline IIb & $\begin{array}{l}\text { Predominantly affecting ororpharyngeal, respiratory muscles, or both. May also have lesser or equal involve- } \\
\text { ment of limb, axial muscles or both }\end{array}$ \\
\hline III & $\begin{array}{l}\text { Moderate weakness affecting other than ocular muscles. May also have ocular muscle weakness of any sever- } \\
\text { ity }\end{array}$ \\
\hline IIIa & $\begin{array}{l}\text { Predominantly affecting limb, axial muscles, or both. May also have lesser involvement of oropharyngeal, } \\
\text { respiratory muscles or both }\end{array}$ \\
\hline IIIb & $\begin{array}{l}\text { Predominantly affecting ororpharyngeal, respiratory muscles, or both. May also have lesser or equal involve- } \\
\text { ment of limb, axial muscles or both }\end{array}$ \\
\hline IV & $\begin{array}{l}\text { Severe weakness affecting other than ocular muscles. May also have ocular muscle weakness of any severity } \\
\text { IVa }\end{array} \begin{array}{l}\text { Predominantly affecting limb, axial muscles, or both. May also have lesser involvement of oropharyngeal, } \\
\text { respiratory muscles or both }\end{array}$ \\
\hline IVb & $\begin{array}{l}\text { Predominantly affecting ororpharyngeal, respiratory muscles, or both. May also have lesser or equal involve- } \\
\text { ment of limb, axial muscles or both }\end{array}$ \\
\hline V & $\begin{array}{l}\text { Defined by intubation, with or without mechanical ventilation, except when employed during routine post- } \\
\text { operative management }\end{array}$ \\
\hline
\end{tabular}


Table 2. Participants' characteristics $(n=30)$.

\begin{tabular}{cccccc}
\hline $\begin{array}{c}\text { MGFA } \\
\text { Classification }\end{array}$ & $\begin{array}{c}n \\
(\%)\end{array}$ & $\begin{array}{c}\text { Gender } \\
\text { (Male:Female) }\end{array}$ & Age (mean \pm SD) & $\begin{array}{c}\text { Positive AChRs } \\
\text { antibody }\end{array}$ & $\begin{array}{c}\text { Thymus } \\
\text { thymoma }\end{array}$ \\
\hline I & $7(23.3 \%)$ & $5: 2$ & $34.5 \pm 8.6$ & 3 & 2 \\
\hline IIa & $7(23.3 \%)$ & $1: 6$ & $46.2 \pm 11.6$ & 4 & 2 \\
\hline IIb & $7(23.3 \%)$ & $4: 3$ & $57.5 \pm 6.7$ & 7 & 2 \\
\hline IIIa & $6(20.0 \%)$ & $0: 6$ & $50.3 \pm 11.1$ & 6 & 1 \\
\hline IIIb & $2(6.7 \%)$ & $0: 2$ & $64.5 \pm 6.3$ & 2 & 0 \\
\hline IVa & $1(3.3 \%)$ & $0: 1$ & $48 \pm 0.0$ & & 8 \\
\hline Total & $30(100 \%)$ & $10: 20$ & $48.57 \pm 2.4$ & 22 & \\
\hline
\end{tabular}

Legend: MGFA - Myasthenia Gravis Foundation of America, AChRs - acetylcholine receptors.

Table 3. CMAP amplitude decrease (\%) between the first and fourth or fifth stimuli

\begin{tabular}{ccccccc}
\hline & \multicolumn{2}{c}{ Frontalis muscle } & \multicolumn{2}{c}{ Trapezius } & \multicolumn{2}{c}{ Abductor digiti minimi } \\
\hline \multicolumn{2}{c}{ Right } & Left & Right & Left & Right & Left \\
\hline $\begin{array}{c}\text { Group I } \\
(\mathrm{n}=7)\end{array}$ & $7.7 \pm 1.8$ & $7.7 \pm 2.3$ & $7.2 \pm 0.6$ & $7.5 \pm 0.6$ & $5.5 \pm 1.1$ & $3.3 \pm 0.9$ \\
\hline $\begin{array}{c}\text { Group a } \\
(\text { IIa, IIIa, IVa) } \\
(\mathrm{n}=14)\end{array}$ & $9.7 \pm 7.1$ & $8.1 \pm 8.4$ & $10.3 \pm 6.2$ & $9.2 \pm 4.9$ & $4.7 \pm 4.0$ & $3.9 \pm 6.4$ \\
\hline $\begin{array}{c}\text { Group b } \\
(\text { IIb, IIIb) } \\
(\mathrm{n}=9)\end{array}$ & $15.3 \pm 5.9$ & $11.4 \pm 4.8$ & $11.1 \pm 2.0$ & $13.1 \pm 4.0$ & $4.0 \pm 5.9$ & $5.5 \pm 3.9$ \\
\hline Total & $10.0 \pm 7.6$ & $9.9 \pm 5.3$ & $9.6 \pm 5.8$ & $10.0 \pm 4.5$ & $4.6 \pm 4.3$ & $4.3 \pm 5.0$ \\
\hline
\end{tabular}

Legend: CMAP - Compound muscle action potential.

\section{RESULTS}

Patients' characteristics

In the sample of 30 patients diagnosed with $\mathrm{MG}$, 20 were female (66.7\%), 10 were male (33.3\%), and the sample had a mean age of $48.57 \pm 2.4$ years (range: 21-69 years). Of these, 17 patients had an early onset ( 50 years, $56.7 \%$ ) and 13 participants a late onset (43.3\%). No association was found between gender and age at onset of MG $(\mathrm{p}=0.794)$.

Clinically, 26 patients had ptosis (83.3\%), 21 had diplopia (70\%), 19 had limb weakness (63\%), 15 had been diagnosed with dysphagia (53.3\%), and 10 had dysarthria (33.3\%). Further, 25 patients had symptoms that became more severe with movement (83.3\%). All patients' symptoms were alleviated by anticholinesterase agents. Based on the MGFA classification ${ }^{15}, 14$ patients were in the mild groups (I, IIa) $(46.6 \%)$, and 16 were in the more severe groups (IIb to IV) (54\%). Additionally, 8 patients reported a history of thymus surgery (20\%) and 22 patients had a positive AChR antibody test (73.3\%) (Table 2).

\section{RNS test}

21 patients had a positive RNS test result (70\%). Patients in MGFA groups I a (IIa, IIIa, and IVa), and b (IIb, IIIb) received $42.9 \%, 64.2 \%$, and $100 \%$ of the positive RNS test results, respectively. Decreases in
CMAP amplitude between the first and fourth or fifth stimuli were significantly different between the right and left frontalis muscle $(\mathrm{p}=0.041)$, as well as the right and left trapezius muscle $(\mathrm{p}=0.031)$. There was no significant difference in the abductor digiti minimi $(p>0.05)$. Patients in group $b$ had the greatest CMAP differences (Table 3).

The trapezius was the most affected muscle in patients with a positive RNS test $(\mathrm{n}=18,85.7 \%)$, which was significantly different from other groups $\left(\chi^{2}=18.09, p=0.03\right)$. Conversely, the abductor digiti minimi only accounted for 7 of the patients recieving positive RNS tests (33.3\%), which significantly differed between patient groups $\left(\chi^{2}=14.56, p=0.012\right)$. Lastly, the frontalis muscle result did not show any significant differences between patient groups $\left(\chi^{2}=4.7, p=0.452\right)$.

\section{Associations between clinical symptoms and RNS test results}

Table 4 shows that patients in MGFA group II or higher recieved the highest number of positive RNS test results (78.3\%). There was a significant relationship between the presence of AChR antibodies and a positive RNS test result ( $\mathrm{p}=0.0041 ; \mathrm{OR}=19 ; \mathrm{CI}$ $95 \%$ of $2.54-141.93)$. 
Table 4. Associations between clinical characteristics and RNS test results $(n=30)$

\begin{tabular}{|c|c|c|c|c|c|}
\hline \multirow{2}{*}{\multicolumn{2}{|c|}{ Clinical characteristics }} & \multirow{3}{*}{$\begin{array}{c}\text { Total } \\
23\end{array}$} & \multicolumn{2}{|c|}{ RNS test } & \multirow{2}{*}{$\begin{array}{c}\text { Fisher's exact test } \\
\text { (P value) }\end{array}$} \\
\hline & & & Positive & Negative & \\
\hline \multirow{2}{*}{ MGFA Classification } & II, III, IV & & $18(78.3 \%)$ & $5(21.7 \%)$ & \multirow{2}{*}{0.0868} \\
\hline & I & 7 & $3(42.8 \%)$ & $4(57.2 \%)$ & \\
\hline \multirow{2}{*}{ AChR antibodies } & Positive & 22 & $19(86.3 \%)$ & $3(13.6 \%)$ & \multirow{2}{*}{0.0041} \\
\hline & Negative & 8 & $2(25.0 \%)$ & $6(75.0 \%)$ & \\
\hline \multirow{2}{*}{ Thymus thymoma } & Yes & 8 & $6(75.0 \%)$ & $2(25.0 \%)$ & \multirow{2}{*}{0.7190} \\
\hline & $\mathrm{No}$ & 22 & $15(68.2 \%)$ & $7(31.8 \%)$ & \\
\hline
\end{tabular}

Legend: MGFA - Myasthenia Gravis Foundation of America, AChRs - acetylcholine receptors.

\section{Discussion}

This study investigated the associations betewen clinical and presenting characteristics of $\mathrm{MG}$ patients and $M G$ patients were more likely to be female than male (female/male ratio of $2 / 1$ ), which was in agreement with previously published work by Gilhaus and Tzartos $^{4}$. This was reported to be due to the effect of the hormone estrogen in inducing MG, especially women under the age of 50 years $^{4}$. Furthermore, the appearance of autoimmune antibodies such as AChR antibodies has been strongly associated with MG. Our results demonstrated that $73.3 \%$ patients tested positive for AChR antibodies and $20 \%$ had received thymus surgery (i.e., thymoma), whereas previous studies have reported $80 \%$ of patients being positive for $\mathrm{AChR}$ antibodies and $10-15 \%$ having thymoma ${ }^{2,5,18}$. These differences may be attributed to population variance, sample size, and socio-demographic differences between samples. Another study conducted in Vietnam by Phan Le Hieu et al. (2014) also reported similar results, with a female/male ratio of $1.96 / 1$, and $91.3 \%$ of MG patients testing positive for AChR antibodies ${ }^{19}$.

MGFA classification grouped patients according to their disease characteristics into groups I, IIa, IIb, IIIa, IIIb, and IVa. Within our sample of 30 patients, $23.3 \%, 46.6 \%, 26.7 \%$, and $3.3 \%$ were classified in groups I, II, III, and IV, respectively. This trend differs slightly from that found by Popperud and Boldingh, who reported $29 \%, 43 \%, 26 \%$, and $9 \%$ of patients classified into groups I, II, III, and IV ${ }^{18}$, respectively. While these numbers are small, there may well also be differences in the research design and patient socio-demographic factors. In the present study, the number of patients in each MGFA subgroup (I, IIa, IIb, IIIa, IIIb, and IVa) was small, with only one patient in group IVa. Therefore, we divided patients into 3 sub-groups according to the predominant signs and symptoms at the time of the neurophysiologic investigation: group I (ocular); group a (axial, limb-girdle, including those with mild, moderate and severe disease), and group b (bulbar, including those with mild, moderate, and severe disease). This re-classification was conducted with reference to a similar study by Costa et al. ${ }^{9}$

The American Association of Neuromuscular \& Electrodiagnostic Medicine has recommended utilizing the non-invasive RNS test for MG diagnosis. The test has been demonstrated to provide a sensitivity of between 30 and $70 \%{ }^{10,17}$. Our results demonstrated that $70 \%$ of the MG patients had positive RNS test result, which was in agreement with reports by Joao Costa $(75 \%)^{9}$ and Bou Ali $(82 \%)^{20}$. Similarly, our finding of significant CMAP differences in the frontalis and trapezius muscle groups, which were associated with MGFA classification groups is also in line with previous work ${ }^{9}$.

Finally, with a high incidence of the presence of $\mathrm{AChR}$ antibodies in $\mathrm{MG}$ patients, this antibody test is considered the gold standard in the diagnosis of MG. A significant association was found between RNS outcomes and AChR antibody levels ( $p$ $=0.0041$ ). Therefore, in cases where patients are unable to undergo AChR antibody quantitation, RNS test may serve as an effective and accurate method for diagnosing and monitoring MG. In contrast, a study by Jin Yian et al. found no such association between RNS responses and AChR antibody levels $(p>0.05)^{21}$. The association is likely to be influenced by the epidemiological features of the research population, and as such needs further investigation to explore other correlated factors influencing these two measures. Therefore, the diagnostic use of RNS in cases of suspected MG should be approached with careful consideration.

\section{Limitations of the study}

This study has some limitations. Firstly, the study sample size was small. MG is a rare autoimmune disease, with a low incidence of the disease in community. According to data published over the past 50 years by Phillips, the prevalence of MG is 20.4 per 100,000 population, with a new case rate of $5-30$ 
cases per 1,000,000 population each year ${ }^{22}$. Secondly, our study design included conducting RNS in only three muscle groups (frontalis, trapezius, and abductor digiti minimi), whereas it has been suggested that the sensitivity of the technique can be improved ${ }^{20}$.

\section{Conclusions}

The findings of this study will be of interest for physicians investigating the pathophysiological mechanisms of MG, to advance diagnostic and monitoring methods, including the utilization of the RNS test. RNS still shows promise when used in combination with classification measures such as the MGFA in providing an alternative method for the diagnosis and monitoring of MG, particularly in cases where AChR antibody quantitation is not appropriate. These findings may be useful for the future application of electroneurology diagnostic techniques in neuromuscular diseases. Further studies are needed to assess the diagnostic usefulness of RNS of the lower limb muscle groups in investigating MG.

\section{Author Contributions:}

Conceptualization, T.K.A.P. and K.T.N.; methodology, T.K.A.P. and T.T.T.T.; software, T.K.A.P. and V.D.T.; validation, K.T.N.; formal analysis, P.V.P. and V.D.T.; investigation, T.K.A.P.; resources, S.P.H.N. and P.V.P.; data curation, T.K.A.P. and T.T.T.T; writing-original draft preparation, T.K.A.P.; writing-review and editing, T.K.A.P., R.S.D. and V.D.T.; visualization, T.K.A.P. and B.T.N.; supervision, B.T.N., T.D.L.; project administration, T.D.L. All the authors have read and agreed with the final version of the article.

\section{Funding}

No funding for this study.

\section{Ethics approval and consent to participate}

"The authors declare that all the procedures and experiments of this study respect the ethical standards in the Helsinki Declaration of 1975, as revised in 2008(5), as well as the national law. In addition, the study was approved by the ethics committee of the Hanoi Medical University (IRB00003121, reference NCS04/DHYHN-HDDD, date 29/03/2019). Informed consent was obtained from all the patients included in the study."

\section{Competing interests}

"The authors declare no conflict of interest regarding this article."

\section{Acknowledgements \\ None.}

\section{References}

1. Jaretzki A, Barohn RJ, Ernstoff RM, et al. Myasthenia gravis: recommendations for clinical research standards. Task Force of the Medical Scientific Advisory Board of the Myasthenia Gravis Foundation of America. Neurology. 2000;55(1):16-23.

2. Gilhus NE, Verschuuren JJ. Myasthenia gravis: subgroup classification and therapeutic strategies. Lancet Neurol 2015;14:1023-1036.

3. Pasnoor M, Dimachkie MM, Farmakidis C, Barohn RJ. Diagnosis of myasthenia gravis. Neurologic Clinics. 2018;36(2):261-274.

4. Gilhus NE, Tzartos S, Evoli A, et al. Myasthenia gravis. Disease Primer. 2019;5:30.

5. Matthew N, Meriggioli DBS. Autoimmune myasthenia gravis: emerging clinical and biological heterogeneity. Lancet Neurol. 2009;8:475-490.

6. Howard JF. Electrodiagnosis of disorders of neuromuscular transmission. Physical Medicine and Rehabilitation Clinics of North America. 2013;24(1):169-192.

7. Preston DC, Shapiro BE. Neuromuscular junction disorders. In: Preston DC, Shapiro BE, eds. Electromyography and Neuromuscular Disorders (Third Edition). London: W.B. Saunders; 2013:529-548.

8. Padua L, Caliandro P, Di Iasi G, Pazzaglia C, Ciaraffa F, Evoli A. Reliability of SFEMG in diagnosing myasthenia gravis: Sensitivity and specificity calculated on 100 prospective cases. Clinical Neurophysiology. 2014;125(6):1270-1273.

9. Costa J, Evangelista T, Conceição I, Carvalho MD. Repetitive nerve stimulation in myasthenia gravis-relative sensitivity of different muscles. Clinical Neurophysiology. 2004;115(12):2776-2782.

10. AAEM Quality Assurance Committee. Practice parameter for repetitive nerve stimulation and single fiber emg evaluation of adults with suspected myasthenia gravis or lamberteaton myasthenic syndrome: Summary statement. Muscle Nerve. 2001;24:1236-1238.

11. Abraham A, Alabdali M, Alsulaiman A, et al. Repetitive facial nerve stimulation in myasthenia gravis $1 \mathrm{~min}$ after muscle activation is inferior to testing a second muscle at rest. Clinical Neurophysiology. 2016;127(10):3294-3297.

12. Liik M, Punga AR. Repetitive nerve stimulation often fails to detect abnormal decrement in acute severe generalized myasthenia gravis. Clinical Neurophysiology. 2016;127:34803484.

13. Gajdos P, Tranchant C, Clair B, et al. Treatment of myasthenia gravis exacerbation with intravenous immunoglobulin. Arch Neurol. 2005;62:1689-1693.

14. Fan L, Ma S, Yang Y, Yan Z, Li J, Li Z. Clinical differences of early and late-onset myasthenia gravis in 985 patients. Neurological Research. 2019;41(1):45-51.

15. Jaretzki A, Barohn RJ, Ernstoff RM, et al. Myasthenia gravis: recommendations for clinical research standards. Task Force of the Medical Scientific Advisory Board of the Myasthenia Gravis Foundation of America. Ann Thorac Surg. 2000;55(1):16-23.

16. Niks EH, Badrising UA, Verschuuren JJ, Van Dijk JG. Decremental response of the nasalis and hypothenar muscles in myasthenia gravis. Muscle Nerve. 2003;28:236-238.

17. AAEM Quality Assurance Committee. Literature review of the usefulness of repetitive nerve stimulation and single fiber EMG in the electrodiagnostic evaluation of patients with suspected myasthenia gravis or Lambert-Eaton myasthenic syndrome. Muscle Nerve. 2001;24: 1239-1247. 
18. Popperud TH, Boldingh MI, Rasmussen M, Kerty E. Juvenile myasthenia gravis in Norway: Clinical characteristics, treatment, and long-term outcome in a nationwide population-based cohort. European Journal of Paediatric Neurology. 2017;21(5):707-714.

19. Hieu PT. Assessing the role of concentration of acetylcholine receptor autoantibodies testing in diagnosis of myasthenia gravis. Journal of Military Pharmaco - Medicine. 2015;3:109-112.
20. Bou Ali H, Salort-Campana E, Grapperon AM, et al. New strategy for improving the diagnostic sensitivity of repetitive nerve stimulation in myasthenia gravis. Muscle Nerve. 2017;55(4):532-538.

21. Yin J, Wen S, Liu Y, et al. Comparison of diagnosis value for new onset myasthenia gravis by many clinical auxiliary examinations. Neural Regeneration Research. 2007;2(7):446-448.

22. Phillips LH. The epidemiology of myasthenia gravis. Seminars in Neurology. 2004; 24(1):17-20. 